\section{EDTTORIAL BOARD}

Leanne Alworth, DVM, MS, DACLAM Assistant Director/Attending Veterinarian, University of Georgia, Athens, GA

Lida Anestidou, DVM, PhD

Program Officer, Institute for Laboratory Animal Medicine,

National Academies, Washington, DC

Charmaine Foltz, DVM, DACLAM

Director, Division of Veterinary Resources, NIH, Bethesda, MD

Paul Houghton

CEO, Biologist, Primate Products, Redwood City, CA

Robert F. Hoyt, Jr., DVM, MS, DACLAM

Chief, Laboratory Animal Medicine and Surgery

National Heart Lung and Blood Institute, NIH, Bethesda, MD

Mary Lou James, BA, RLATC

Consultant, Regulatory Compliance, St. Louis, MO

Alicia Z. Karas, DVM, MS, DACVA

Assistant Professor, Anesthesia, Department of Clinical Sciences,

Cummings School of Veterinary Medicine, Tufts University, North Grafton, MA

Bruce W. Kennedy, MS, RLATG, CMAR, CPIA

Compliance Associate and Lecturer, Office of Research,

Compliance Associate and Lecture
Cal Poly Pomona, Pomona, CA

C. Max Lang, DVM, DACLAM
Professor and Chairman, Department of Comparative Medicine,

Professor and Chairman, Department of Comparative Medicine,
Milton S. Hershey Medical Center, Pennsylvania State University, Hershey, PA

Richard H. Latt, DVM, DACLAM

President, Mispro Biotech Services Inc., Montreal, Quebec, Canada

Sherry M. Lewis, PhD

Nutritionist/Research Scientist,

National Center for Toxicological Research, Jefferson, AR

Carol Cutler Linder, PhD

Assistant Professor of Biology, New Mexico Highlands University, Las Vegas, NM

John A. Maher, MS, MBA, CMAR, RLATG

Senior Manager, Comparative Medicine, Pfizer, Pearl River, NY

Jörg Mayer, Dr.med.vet., MSc, MRCVS, DABVP (ECM)

Associate Professor of Zoological Medicine,

College of Veterinary Medicine, University of Georgia, Athens, GA

Daniel R. Schwartz, MS, DVM, DACLAM

Attending Veterinarian, Wesleyan University, Middleton, CT

John Curtis Seely, DVM, DACVP

Veterinary Pathologist,

Experimental Pathology Laboratories, Research Triangle Park, NC

Jo Ellen Sherow, BS, LATG

Director, Research Compliance, Ohio University, Athens, $\mathrm{OH}$

Jerald Silverman, DVM, DACLAM

Professor and Director, Department of Animal Medicine,

University of Massachusetts Medical School, Worcester, MA

Michael K. Stoskopf, DVM, PhD, DACZM

Professor and Director of Environmental Medicine Consortium,

College of Veterinary Medicine, North Carolina State University, Raleigh, NC

James Taylor, DVM, MS, DACLAM

Management Consultant, Derwood, MD

Robert H. Weichbrod, PhD, MBA, RLATG

Animal Program Administrator, National Eye Institute, NIH, Bethesda, MD

Axel Wolff, MS, DVM

Director, Division of Compliance Oversight, OLAW, NIH, Bethesda, MD

\section{Sciatic denervation in golden-mantled ground squirrels (Callospermophilus lateralis)}

The mechanisms regulating disuse atrophy of muscle and bone that results from periods of inactivity are poorly understood. In contrast with non-hibernating species, many hibernating species such as ground squirrels demonstrate little to no disuse atrophy during prolonged periods of limb disuse, thus providing natural models for how disuse atrophy may be avoided. In rodent models developed to study disuse atrophy, immobilization is induced by prolonged cage restraint, hind limb unloading, tenotomy, sciatic nerve block or sciatic denervation. Each approach offers advantages and disadvantages, but in less tractable species such as wild-caught hibernating rodents, the sciatic denervation model is superior in terms of both animal welfare and applicability to the characteristics of natural cases of disuse atrophy. Nerve transection is the preferred method of sciatic denervation, but potentially painful sequelae to this procedure and autotomy (self-mutilation by chewing) have been reported. Valeri Sarukhanov and colleagues describe specific refinements to their surgical approach to sciatic denervation in golden-mantled ground squirrels (Callospermophilus lateralis) that minimize the risk of autotomy and other post-operative complications.

See page 203

\section{Safety of injectable anesthetics in female Wistar rats}

There are several advantages of using injectable anesthetics, such as a combination of medetomidine and ketamine, rather than inhalational drugs to induce general anesthesia in rats undergoing invasive procedures. Although the use of medetomidine and ketamine in nonpregnant rats is widespread, there is little evidence to demonstrate their safety and efficacy in pregnant rats. After noticing a high incidence of morbidity and mortality in pregnant Wistar rats given medetomidine and ketamine for anesthesia, Lauren Callahan et al. further investigated the efficacy and safety of this anesthetic combination in both pregnant and nonpregnant Wistar rats by measuring the duration of anesthesia and monitoring several parameters. The authors suggest that researchers using medetomidine and ketamine to anesthetize Wistar rats should carefully monitor the rats in order to minimize mortality.

See page 208 